\title{
La felicidad o el fin olvidado de la política moderna
}

\section{Happiness or the Forgotten Aim of Modern Politics}

\author{
Alexánder Hincapié-García (i) https://orcid.org/0000-0001-6828-2786 \\ Universidad de San Buenaventura Medellin, Colombia, alexander.bincapie@usbmed.edu.co \\ Bibiana Escobar-García (i) https://orcid.org/0000-0001-8852-5466 \\ Tecnológico de Antioquia Institución Universitaria,Colombia, bibiana.escobar@tdea.edu.co
}

Recepción:

\begin{abstract}
Article derived from the concluded research: The bodies of exception. The main objective is to examine the conditions of possibility created by the State modern policy so that men and women can lead a good life. The theoretical-methodological perspective is taken from the philosophy of Walter Benjamin, Michel Foucault and Giorgio Agamben. The methodological procedure is montage (Benjamin, 2013 and 2015). With this, we mean the work of relating perspectives to produce a kind of critical interpretation with respect to the present. The montage is organized in two moments, one destructive and the other constructive. Among the conclusions, we can advance the following: happiness is a forgotten human end, verifying that suffering has become a silent waste for politics; something which it does not respond to.
\end{abstract}

Key words: happiness, politics, State, exception, modernity.

Resumen: Este artículo se deriva de la investigación finalizada: Los cuerpos de la excepción. El objetivo principal consiste en examinar las condiciones de posibilidad creadas por la política moderna del Estado, para que hombres y mujeres puedan crear una vida buena. La perspectiva teórico-metodológica se retoma de la filosofía de Walter Benjamin, Michel Foucault y Giorgio Agamben. El procedimiento metodológico es el montaje (Benjamin, 2013 y 2015). Por esto se entiende el trabajo de relacionar perspectivas para producir un tipo de interpretación crítica respecto al presente. El montaje se organiza en dos momentos: uno destructivo y otro constructivo. Dentro de las conclusiones se puede adelantar lo siguiente: la felicidad es un fin humano olvidado, confirmándose que el sufrimiento se ha convertido en un desecho mudo para la política; algo por lo que no responde.

$06 / 02 / 2018$

Palabras clave: felicidad, política, Estado, excepción, modernidad. 


\section{Introducción $^{1}$}

En el capítulo 1 del libro VII de la Política, Aristóteles (2007) sostiene que hay tres tipos de bienes: los externos, los del cuerpo y los del alma. Los bienes externos y los del cuerpo son necesarios, incluso deseables, pero no pueden perseguirse por encima de los bienes del alma, pues perseguidos en exceso, por fuerza, causan daño. Entre tanto, la abundancia en los bienes del alma, esto es la prudencia y la virtud, no producen daño alguno al individuo o a la ciudad. Así, para Aristóteles, la felicidad (eudaimonia) a la que el individuo y la ciudad pueden aspirar será acorde con dichos bienes. Por ello hay que considerar la pregunta: ¿Qué felicidad puede haber si falta la prudencia y la virtud?

De manera temporal, Aristóteles (2007: 392) concluye que “[...] el mejor género de vida para el individuo en particular y para las ciudades en común es el que se acompaña de una virtud dotada de recursos suficientes como para cumplir acciones virtuosas". Se está reconociendo un vínculo entre los bienes externos y los del cuerpo con los bienes del alma, que son de donde proceden las acciones virtuosas, aunque ese vínculo no es de determinación. Los bienes externos y los bienes del cuerpo, que pueden asimilarse con la propiedad y la salud, tienen lugar al lado de los bienes del alma que son los inextricablemente relacionados con las acciones virtuosas o buenas. Vigo (2007) sostiene que no es la virtud, como una posesión, sino el ejercicio de las acciones virtuosas o buenas lo que, en su conjunto, adquiere el sentido que constituye la felicidad.

En capítulo 2 del mismo libro, Aristóteles (2007) se pregunta por el género de vida preferible: uno que consista en participar de la vida política y comunitaria de la ciudad o, por el contrario, uno en el que, como pasa con el extranjero, se esté liberado de esta participación. Igualmente, se pregunta por el mejor régimen político: uno en el que todos deban participar de la vida de la comunidad o uno en el que la mayoría sí, aunque no todos de manera absoluta.

El filósofo encuentra forzoso reconocer que el mejor régimen político será aquel donde todos los hombres, cualesquiera que estos sean, puedan vivir con felicidad. Ahora bien, dado que determinar el contenido de la felicidad no es sencillo, “[...] es propio del buen legislador estudiar cómo una ciudad, el género humano o toda otra comunidad participarán de una vida buena y

1 Parte del proyecto de investigación Los cuerpos de la excepción, financiado por la Universidad Autónoma Latinoamericana y la Universidad de San Buenaventura Medellín. Identificado con el Código: FT-INV-O12. El acta de inicio se firmó en octubre de 2014 y la de cierre el 19 de febrero de 2016 con el código INPR. 01.V1. 
de la felicidad que les es asequible" (Aristóteles, 2007: 397). Un avance de lo que Aristóteles desbroza se halla en el capítulo 13. Aquí el estagirita se propone dilucidar el mejor régimen político, y este es el que permite el buen gobierno de la ciudad. Esto significa que el ejercicio del buen gobernar es el que hace posible la felicidad; es decir, aquel que hace posible que los seres humanos puedan dar forma a vidas logradas. En este punto, a la pregunta ¿qué es la felicidad?, Aristóteles (2007: 426-427) responde que “[...] es una actualización y ejercicio acabado de la virtud, y ello no en sentido relativo, sino en sentido absoluto".

Para Vigo (2007), Aristóteles ofrece una distinción entre tres tipos de fines. Los primeros son los fines instrumentales, es decir, los que sirven de medios para otras cosas y no son buscados por sí mismos. Este es el caso de los instrumentos o las herramientas. Los segundos son los fines que tienen la doble cualidad de ser buscados como medios para otras cosas o pueden ser buscados por sí mismos. Téngase por caso la salud. Por último, están los fines deseados por sí mismos y no en función de otras cosas. Estos fines, como puede esperarse, son los que responden al más elevado de la vida: la felicidad.

Aristóteles supone que en cuanto a estos fines hay consenso al relacionar la felicidad como el fin último (Vigo, 2007). Aun así, el problema es determinar el contenido de dicho fin. Las discrepancias abundan, habrá quienes piensan que la felicidad se encuentra en los bienes materiales o los que imaginan que la felicidad no se alcanza a través de bienes inmediatos. No es de extrañar que quien sufre la pobreza, imagina la felicidad como riqueza. El enfermo, por su parte, idealiza la felicidad en la salud.

Sin embargo, Aristóteles no supone que cualquier representación sirva para establecer el contenido de la felicidad y, de hecho, tampoco supone que dicho contenido depende de los deseos del individuo en tanto agente de su vida. La felicidad debe comprenderse "[...] a través de una concepción normativa, que apunta a lo que sería el bien real del agente, que corresponde en virtud de la constitución de sus propias capacidades y que puede no coincidir con lo que el propio agente desea de hecho" (Vigo, 2007: 194).

Aristóteles descubre que la meta final del hombre, también entendida como meta política, tiene que ver con la felicidad y con la aspiración a vivir una vida buena. Aunque la cuestión sigue pendiente en la medida en que se podría caer en la confusión de imaginar que la felicidad es un placer momentáneo, un instante fugaz, la satisfacción de un deseo o la experiencia de un placer. Si se diera por cierta dicha confusión, se estaría suponiendo que la felicidad se puede fundamentar en el plano de lo empírico, con lo cual se pierde 
la posibilidad de una fundamentación de la felicidad en términos de lo universal y necesario. Para Annas (2004: 67) debe quedar claro que la felicidad de la que se habla es aquella que solamente puede reconocerse a la totalidad de la vida: “[...] la felicidad se aplica a la vida como un todo" y se manifiesta en las posibilidades para que los seres humanos puedan desarrollar y percibir sus vidas como vidas logradas. En otras palabras, la felicidad vendría a ser una forma de vida, asociada a la virtud y a las acciones que de esta se desprenden. No es un evento o experiencia particular que satisface un deseo momentáneo y caprichoso.

La felicidad tampoco es una forma de vida liberada de las condiciones materiales y de las posibilidades políticas que deben construirse para que las vidas humanas puedan constituirse en vidas logradas. De cierta manera, la felicidad depende del movimiento dialéctico entre las capacidades humanas y el gobierno de la ciudad. Por un lado, los individuos deben desarrollar las capacidades de las que disponen para dar forma a sus vidas. Pero, por el otro, solo con el concurso del gobierno de la ciudad las vidas de los seres humanos pueden ser buenas. Con esta interpretación se está cerrando la posibilidad de hacer depender la felicidad y la vida buena, en exclusiva, de la voluntad del individuo. También se cierra la posibilidad de espiritualizarla, como bien cuestiona Marcuse (2011), con el propósito de reconciliarla con cualquier forma de gobierno, así este sea injusto. ${ }^{2}$

Este sucinto marco interpretativo con el que se recuerda la importancia de la felicidad dentro de los fines políticos de la Antigüedad clásica, contrasta con la ruptura histórica que supone la Modernidad. Para referirse a esta ruptura, Foucault (2002) estudia el umbral de modernidad biológica. Por esto se entiende la coyuntura en la cual la especie se pone a sí misma en el corazón de sus intervenciones políticas. En otras palabras, la coyuntura expresa el juego del hombre con el hombre en el campo de unas intervenciones que se dan para sí la vida entera. A juicio de Foucault (2002: 173), durante dos milenios el hombre no fue algo distinto a lo imaginado por Aristóteles: "[...] un animal viviente y además capaz de una existencia política”.

Por su parte, el hombre moderno es un animal que en la política pone en juego su condición de ser viviente. La explicación que puede arrancarse al mismo Foucault, estriba en que el hombre comienza a definirse por la historia y, en esa definición, la vida es lo exterior que, extrañamente, está al interior de una historicidad profusa en técnicas de saber y poder.

2 Para un estudio comparativo en torno a la felicidad de los antiguos y los modernos, se sugiere el trabajo de Nosetto (2013). También, respecto a la felicidad en la Modernidad, se sugiere el trabajo de Cuesta (2013). En una perspectiva sociológica, diferente a la adoptada en este artículo, puede consultarse el trabajo de Trujano (2013). 
La definición de lo humano por la historia se constituye en un haz de relaciones entre el saber y el poder que hace posible la intervención racional de la vida. No se trata de un gobierno orientado hacia la creación de posibilidades para la felicidad, sino de una política capaz de crear, gestionar, administrar e incrementar la vida. En eso consiste la historicidad del hombre: el hombre convierte la vida en el objeto de su propio vivir. O, en otros términos, el ser humano convierte la vida en el objeto de una incesante máquina antropológica (Agamben, 2007) que, en efecto, no puede disociarse de la figura del Estado moderno y sus instituciones de derecho. El Estado es la máquina antropológica que mezcla las identidades clásicas, dando forma, codificando y descodificando la vida a través de identidades principalmente jurídicas: el preso, el homosexual, el terrorista, el menor de edad, el inmigrante ilegal, entre otras (Agamben, 2005).

La perspectiva teórico-metodológica de la investigación se vincula con la filosofía de Walter Benjamin, Michel Foucault y Giorgio Agamben. Tres fuentes filosóficas indispensables para emprender una lectura crítica de la Modernidad. La perspectiva adoptada aúna teoría y método, en un tipo de ensamble nombrado como montaje por Benjamin (2013 y 2015). Un procedimiento que se sirve de los materiales filosófico-políticos, en este caso resueltos como instrumentos analíticos, para dar forma a un tipo de interpretación que rompa la condescendencia con la que el investigador social da cuenta del presente. De lo que se trata es de armar un tipo de interpretación contraria al liberalismo democrático, que desplaza la resolución de los problemas del presente hacia un futuro incierto que nunca se alcanza y por el cual nadie responde.

Esta perspectiva teórico-metodológica precisa exponer sus momentos. El primero es uno destructivo, como el mismo Benjamin asumió desde el surrealismo. En un sentido explícito, destruir significa poner en duda los valores del liberalismo democrático; mostrarlos como contrarios a una verdadera emancipación de la vida humana. Al segundo momento Benjamin lo identifica como constructivo. Contrario a lo que se pueda imaginar, la característica de este momento no es el optimismo sino el pesimismo. Si el liberalismo democrático vocifera por todos lados la esperanza de heredar un mundo mejor para "nuestros hijos", Benjamin responde declarando la necesidad de un pesimismo activo que muestre que nada puede esperarse, el futuro no está asegurado y, por lo tanto, la urgencia es hacerse cargo del presente.

Este trabajo tiene como supuesto central que la felicidad es el fin olvidado de la política moderna, confirmando que el sufrimiento es un desecho mudo para la política. Algo contra lo cual Foucault (1996) se resistió. 
Además de la introducción ya expuesta y de las conclusiones planteadas en la parte final, en el trabajo se desarrollan dos apartados como resultados y discusión. El primero se titula Política y excepción. En este se plantea que, después de Auschwitz, el estado de excepción, concepto clave de la política moderna, tal como Benjamin avisa, es regla no sólo para los gobiernos totalitarios y fascistas, sino también para los liberales y democráticos, por una suerte de dispositivo que relanza insistentemente la necesidad de la excepción para asegurar el futuro. El segundo apartado lleva por título La Modernidad: sobre la imposible felicidad. Este pone en relación directa a la Modernidad y el capitalismo; señala el carácter aterrador de la orientación de la primera por la novedad y muestra al último como una religión de la culpa incapaz de ofrecer la felicidad.

\section{Política y excepción}

Las instituciones estatales tienen la función de responder por los fines del Estado, dentro de un marco de legalidad y derecho que produce, gestiona y regula la vida social. Llamadas a enfrentar situaciones de urgencia (la guerra, la insurrección o la desobediencia para ilustrar con algunos casos), acuden a figuras como la del estado de excepción para preservar el orden decretado. Una de las características más notorias de la excepcionalidad es la abolición temporal de la separación entre los poderes Legislativo, Ejecutivo y Judicial; por ello, el gobernante o gobierno queda facultado para habilitar las leyes que la excepción reclama; es decir, un derecho que se anula por derecho, para reinaugurar la antigua figura del soberano que ocupa el lugar de la fuerza de ley.

El estado de excepción vincula vida y derecho. Foucault (2002) analiza esta vinculación exponiendo los mecanismos del poder que, en la época Clásica, dan al soberano el derecho a decidir sobre la muerte de los hombres. Foucault (2002) también señala la transformación de estos mecanismos en la Modernidad occidental, lo cual implica el paso del poder soberano a regímenes más pletóricos del poder: anatomopolítico y biopolitico. El primero se dirige a la formación del cuerpo mediante la disciplina (regulación del tiempo y del espacio); el segundo a la invasión de la vida mediante procedimientos de control (censos, estadísticas, segmentación, grupos etarios, poblaciones de riesgo, entre otras formas). Ya no se trata de decretar la muerte, sino de ejercer un gobierno del cuerpo y de la vida que normalice, haga crecer y multiplique las fuerzas disponibles. Para Foucault (2005), esto no significa la demostración del progreso de la humanidad, cosa que por lo demás no le preocupa afirmar o desmentir. Lo que este paso significa tiene que ver 
con una mutación en las formas del castigo y del gobierno que se organizan recurriendo a la observación sistemática, la vigilancia incesante, el examen y la evaluación perenne de los hombres; en últimas, el intento fáustico de controlar absolutamente el cuerpo y la vida.

Resulta paradójico que la normalización del cuerpo (anatomopolitica) y el gobierno de la vida (biopolitica) no anulan la posibilidad de la muerte. Al contrario, si se piensa en el siglo XX, la tentativa de normalizar, hacer crecer y multiplicar las fuerzas corporales y de la vida imbrica la posibilidad del sacrificio a gran escala (la solución final, las masacres, la limpieza social, las desapariciones forzadas, las ejecuciones extrajudiciales y el terrorismo de Estado son sus ejemplos). Agamben (1998) comparte el análisis de Foucault en torno a que el poder que refina el cómo dar forma a los cuerpos y hacer suya la vida, cubriéndoles mediante insidiosas técnicas de gobierno, es uno de los más grandes y decisivos acontecimientos de la Modernidad. El cuerpo y la vida son puestos como sujetos y objetos de un ordenamiento político que procede, gobernando, mediante acuciosos sistemas de penetración y análisis, no exentos de complejos procedimientos pedagógicos.

Pareciera que el estado de excepción es una forma política del poder soberano que cruza, eventualmente, el umbral de la Modernidad, puesto que la soberanía ha sido desplazada por un tipo de poder diferente: anatomopolitico (el cuerpo) y biopolitico (la vida), en los términos de Foucault (2002). No obstante, antes de Foucault, Schmitt (2011) aclara que la soberanía no es otra cosa que el poder de decretar la excepción, y en eso se manifiesta su absoluta actualidad y vigencia. ${ }^{3}$

En apoyo de lo anterior, se podrían citar las fuentes de Tobón (2011), donde se reconoce que la expresión estado de sitio se emplea por vez primera en la Convención Francesa de 1791, como una figura formal para una medida de tipo militar. Es posterior a la Revolución Francesa que el estado de sitio es derivado al Poder Ejecutivo (Tobón 2011). Para profundizar lo antes dicho, con Agamben (1998) se puede referir que la biopolitica es la cara oculta de los distintos modos de gobierno en Occidente, no el modo singular de la Modernidad. Esto quiere decir que la soberanía no desaparece con la biopolitica moderna. Al contrario, se pliega imperceptible, incluso, en el pensamiento y en las formas de gobierno que la niegan. Por ejemplo, el liberalismo y la democracia. De manera acertada, Hernández (2008: 85) sostiene que para Agamben "[...] la política occidental ha sido siempre biopolítica”. Hasta aquí se obtiene que la vinculación entre derecho y vida también puede leerse con los términos estado de excepción y biopolitica.

3 Para un análisis centrado en el concepto de Schmitt, vale la pena remitirse a Atiles-Osoria (2015). 
Agamben (1998) afirma que el argumento de Foucault, con todo lo estimulante que resulta, debe someterse a corrección o, al menos, ampliarse. En primera instancia porque abandona demasiado pronto el análisis de las formas jurídicas o del derecho; es decir, Foucault (2002) señala que la ley no puede separarse de la espada. Sin embargo, el poder en la Modernidad ya no dependerá tanto de la fuerza de ley, sino de su capacidad de penetrar las esferas más básicas de funcionamiento: la subjetividad, la familia, los sistemas de protección social, las prácticas de producción de identidad, entre otras.

Si bien todo es correcto, no por ello las formas jurídicas o del derecho se convierten en anacrónicas. Al contrario, se hacen más eficientes al no demandar de manera permanente la coacción y al servirse, principalmente, de la misma normalización que los hombres comienzan a darse para sí y a ejercer sobre los otros. En segunda instancia, la corrección o el argumento ampliado que Agamben propone se deriva del reconocimiento de que la biopolitica es, al final, el modo de gobierno occidental por excelencia. A pesar de sus olvidos y rupturas, la intervención absoluta y total del cuerpo y de la vida es la aspiración de todo arte de gobernar.

Decretar el estado de excepción es la preservación de un orden que el ejercicio performativo del derecho asimila con la vida misma. Si seguimos a Benjamin (2010a y 2010b), el derecho crea la sacralidad de la vida en el gesto aporético de su reducción. Es el derecho el que instituye el dogma de la vida sagrada y, al tiempo, la reduce al destino que él mismo le señala (Benjamin, 2010c). El estado de excepción que advierte actuar de manera favorable a la vida intensifica su vulnerabilidad, pues los gestos que amenazan el orden que la soberanía quiere preservar, exponen el cuerpo y la vida a consecuencias extremas. Nótese la imagen del Homo Sacer. Agamben (1998) declara que este es quien puede darse muerte, pero cuya vida es insacrificable.

La ambivalencia de esta imagen muestra que al pretender hacer valer la vida humana como un derecho frente al poder soberano, lo que se consigue afianzar es la sujeción de la misma a un poder capaz de dar la muerte. Dicho de otro modo: el estado de excepción no sólo suspende el derecho desde el propio derecho, sino que refuerza el poder de sacrificar la vida, a pesar de que se hable de su crecimiento y multiplicación. ${ }^{4}$

En efecto, el siglo XX pone en relación el estado de excepción con las bondades infinitas e impredecibles de la técnica. Con anterioridad, Benjamin (2012a) sostiene que, al liberar la técnica de cualquier tipo de consideración

4 Para Sucasas (2000), la soberanía se define como el poder que decide sobre la vida. En particular el poder de dar la muerte de facto o dosificada, teniendo presente que no hay otro desenlace posible que no sea fatídico. 
moral, es inevitable la recaída en el fascismo. El caso ejemplar se halla en los campos de exterminio del Tercer Reich (Lager). Toda la técnica moderna puesta al servicio de una política de la muerte y el exterminio para la seguridad, la protección y el perfeccionamiento de una raza superior. Sea, pues, un estado de excepción para continuar soñando el sueño de formar y perfeccionar a los hombres (Runge y Muñoz, 2010; Galcerà, 2016; Piñeres-Sus, 2016 y 2017).

Para Levi (2012), los campos de exterminio son el culmen de la historia ensangrentada de la humanidad, pues unen el viejo fin que solicita eliminar al adversario político y el fin moderno que se propone, por distintos medios, desaparecer pueblos y razas por completo (eugenesia). Por su parte, Agamben (1998) expone a los campos como los lugares por antonomasia de la biopolítica moderna.

Léase que en ellos los hombres son despojados de la condición política. Si se es más preciso, no hay condición política que invista a aquellos que han sido arrojados a una zona de indiferenciación e indiferencia antropológica. Aquí, si se quiere, una nueva acepción para el concepto de campo. Váyase por partes. Levi (2010) afirma que los campos de exterminio son, en su conjunto, la estructura nuclear de la historia moderna y contemporánea, a la vez que su médula oscura. Los campos no son una anécdota histórica y mucho menos el pasado superado. Al contrario, son el corazón mismo del presente y su historicidad (Levi, 2010). Agamben (1998 y 2010), a su vez, añade que, después de Auschwitz, campo es la estructura, dígase paradigmática, del estado de excepción. Del mismo modo, el campo se constituye en el nomos no revelado de la política y, por lo tanto, el espacio político en el cual el hombre moderno puede existir. La cuestión paradojal subyace en que, por un lado, los campos despojan de la condición política y, por el otro, el campo es el espacio político de la existencia humana.

Ahora bien, si se sigue a Levi y a Agamben, puede decirse que campo es el espacio de experimentación humana donde el hombre se pone a prueba a sí mismo y multiplica la capacidad de su destrucción. Esto es, campo significa el espacio histórico y político del presente humano, donde el hombre expulsa al hombre hacia una zona de indiferenciación e indiferencia antropológica. Dicho de otro modo, después de Auschwitz, campo no puede significar otra cosa que zona de experimentación y exterminio. Como constatación, los procedimientos históricos y políticos mediante los cuales el hombre es rebajado a la nuda vida. Insístase: se habla de los campos de concentración porque estos desnudan una lógica de la destrucción que sigue activa. Esta lógica se puede entender como soberana. De hecho, Mate (2003a y 2003b) se pregunta 
si, al convertirse en la estructura política por definición, puede haber algo exterior a los campos.

En este punto se pueden recapitular varias cosas. En primer lugar, como señala Tobón (2011: 69): "El estado de excepción, pues, equivale a la caducidad de un orden regular y constituye el momento político por excelencia, porque sólo en ese momento, y no durante la vigencia de la regularidad del orden, se pone de manifiesto quién es el verdadero soberano". Esto es, la figura del estado de excepción, con todo lo discutida y polémica que pueda resultar, es la figura paradigmática de la política moderna y contemporánea. De hecho, Agamben (1998, 2010 y 2014) advierte que el recurso que relaciona estado de excepción y campos de exterminio no es la voluntad de recordar a los judíos, los gitanos, los homosexuales y los opositores políticos allí sacrificados, sino la necesidad de captar la relación que amarra el presente a una máquina que no cesa de darse para sí el sacrificio de la vida humana.

En segundo lugar, los campos son la demostración empírica de la disuelta frontera entre la vida y el derecho. Disolución en la cual el último término se anula temporalmente para proceder con el sacrificio del primero. Ante esta consumación atroz de la política, es imprescindible revalorar la tesis VIII sobre el concepto de historia de Benjamin (2012b: 309): "La tradición de los oprimidos nos enseña que el 'estado de excepción' en que vivimos es sin duda la regla”. La tesis se hace más aguda cuando permite destacar que derogar la norma que hace legal la excepcionalidad no es realmente un modo efectivo de corregir lo que se normaliza en un estado de excepción. Al contrario, lo que resulta ratificado es la violencia que funda e instituye al derecho y sus formas (Benjamin, 2010c).

Finalmente, Orejuela-Botero (2011: 98) propone “[...] un conjunto de medidas y reformas constitucionales y legales que aumenten la capacidad de los controles parlamentarios para los estados de excepción”. Empero, Ruíz-Gutiérrez (2013) parece responder afirmando que independiente a las transformaciones de los regímenes políticos, el presente del hombre se realiza en un acucioso y complejo campo biopolítico que produce la vida humana como nuda vida. Más allá de todo esto, la misma Ruíz-Gutiérrez demuestra el carácter paradójico de la política: las libertades, los derechos y los espacios por los que los hombres luchan frente a cualquier manifestación soberana de los poderes allanan la oportunidad, para una "[...] creciente inscripción de su vida en el orden estatal, ofreciendo asi un nuevo y más temible asiento al poder soberano del que querian liberarse" (Ruíz-Gutiérrez, 2013: 82).

De momento, se podría matizar lo dicho, afirmando que más que la inscripción de la vida en el orden estatal, se asiste a la captura de la vida 
por el derecho. Toda nueva lucha social que se asienta en el orden jurídico reafirma, de paso, las infinitas posibilidades del derecho para adueñarse de la vida y de los hombres. Tal vez por ello Marx (2012) advertía que, en el despliegue de las fuerzas sociales y políticas, lo que tendría que abrirse paso es la libre asociación entre los hombres. En otras palabras, una política todavía no inventada y que no será posible con las condiciones puestas por la Modernidad (Hincapié, 2014 y 2016).

\section{La Modernidad: sobre la imposible felicidad}

En este punto, las premisas señaladas deben acercarse a la Modernidad capitalista. Aquí cobra relevancia el problema de la relación del hombre con la naturaleza y la relación del hombre consigo mismo. Es aquí donde hay que enfatizar en esa puesta en juego de la condición de lo viviente. Nótese bien. La Modernidad se define como la época en la cual el hombre se forma a partir de sí mismo o como el reino del hombre en la tierra. El punto de referencia, la imagen de su formación, ya no es la tradición, la experiencia o la memoria, sino un tiempo nuevo, el del progreso. Releyendo a Mancera (2005), podría decirse que la percepción apocalíptica del tiempo judeocristiano, siempre a la espera del desenlace que ponga fin al ciclo amargo de la historia, es remplazada por una percepción del tiempo, en términos de progreso, que no puede conducir a otro lugar que no sea el futuro: el tiempo se hace infinito. En consecuencia, la Modernidad se entiende como el vértigo fatal de la atracción repetitiva por la novedad.

En la Obra de los Pasajes, Benjamin (2015: 868) sostiene que esta es la época de lo nuevo "en el contexto de lo ya-siempre-ahí-sido". Después añade que es la época del infierno, donde su pesadumbre es "[...] lo novísimo que se da a cada vez en ese espacio" (Benjamin, 2015: 869). Con esto, no invoca la idea del eterno retorno ni está señalando que la Modernidad es la época de lo siempre igual. Sí advierte que el mundo moderno permanece inalterado por el ciclo repetitivo de lo nuevo y por una orientación lineal y homogénea del tiempo.

En esto consiste lo eterno del infierno. Todo pasa sin que realmente pase nada. En otras palabras, no es en la persecución neurótica de la novedad donde puede hallarse la dinamita de la revolución, sino en la interrupción del tiempo lineal y homogéneo del progreso y en la comprensión aguda de la singularidad de la época o, como dirá el propio Benjamin (2012b: 309), en el esfuerzo por "[...] cepillar la historia a contrapelo". Con esta expresión finaliza la redacción de la tesis VII. Para Löwy (2012), esta tiene un doble sentido: histórico y político. 
El sentido histórico se refiere a la obligación del materialismo histórico de cuestionar la historia de los vencedores oponiéndole la tradición de los vencidos. Con esto, Benjamin (2012b) muestra que la realidad de la historia no son los hechos que el historicista de oficio describe. Muy por el contrario, la realidad no está completa sin la memoria de los vencidos y de los proyectos de una vida feliz que fueron hundidos con los hombres que lucharon por ellos.

El sentido político advierte que la redención de la humanidad no se realiza con el despliegue natural de las cosas. Esto es, no se dará sin la interrupción de todas las formas de dominación que confabulan para naturalizar el estado actual de cosas. Benjamin (2012b) señala que, si no se aprieta la palanca de freno de esa máquina desaforada llamada progreso, la historia no podrá ser nada más que la de los daños, la destrucción y la muerte.

Años antes de la redacción de las tesis, Benjamin afirma que el capitalismo es una religión. Si para Marx la religión no se refiere a ningún contenido real, porque lo que predica es una vida inexistente, Benjamin (1985) percibe algo singular de la Modernidad capitalista: su religiosidad. El capitalismo sirve a las mismas preocupaciones de las antiguas religiones. No es una forma condicionada por la religión como expuso Weber (2003), sino que es en sí mismo una religión. Hay tres características esenciales que permiten dicha comprensión. La primera, el capitalismo es una religión de culto llevada a su máximo extremo: todo gira alrededor suyo. No hay nada que le sea exterior, y si el dinero es la forma determinante de intercambio, entonces ni siquiera las relaciones llamadas íntimas o personales escapan a su determinación.

La segunda característica indica que, sin contener teología o dogma alguno, el capitalismo no reconoce días sagrados o especiales, lo cual introduce una dimensión demoniaca en la temporalidad. No hay interrupción en el tiempo: todo le pertenece. Por ello, todos los días son suyos y así los reclama como días para su culto. Adviértase, por ejemplo, el impulso permanente e incesante hacia el consumo. Finalmente, el capitalismo es una religión culpabilizante. Es probable que la única religión que no remite a expiación alguna, sino a la implantación de la culpa/deuda permanente. Con el capitalismo, entonces, el efecto lacerante de un plexo de culpa, siempre en aumento, que domina la existencia. Pero, más allá de esto, lo históricamente desconcertante es que no es una religión de la transformación sino de la destrucción (zerstörung).

En los Manuscritos de economía y filosofía, Marx (2007) demuestra que el capitalismo es la destrucción física y moral del obrero. No obstante, Benjamin (1985) va más allá al señalar que esa destrucción, que no 
es solo la del obrero, se transfigura hasta convertirse en una función religiosa. De hecho, Benjamin se arriesga en la corrección de Nietzsche. A su juicio, Dios no ha muerto, este se ha plegado al destino del hombre, esto es, comparte su caida en una religión de la desesperanza, sin rasgo alguno de trascendencia. Benjamin interpreta que la religiosidad del capitalismo no se entiende en los términos de una inclinación hacia bienes morales superiores.

$\mathrm{Al}$ contrario, esta religiosidad tiene por motivo inclinaciones prácticas, equiparables a las formas religiosas paganas, dentro de las cuales los hombres irreligiosos son vistos como incapacitados, tal cual el capitalismo considera a los hombres improductivos. Nuevamente, los planteamientos de Agamben (1998) permiten ampliar la descripción presentada en la medida en que este asevera que sin la biopolitica el capitalismo no habría tenido oportunidad de florecer y, ya se ha dicho, la biopolitica es la reducción de la vida de los hombres a nuda vida y, por lo tanto, la imposibilidad de su felicidad.

\section{Conclusiones}

Los acontecimientos que produce la Modernidad no pueden separarse de un dominio nefasto de la naturaleza por la técnica, del sojuzgamiento del hombre por el hombre en términos de clase, de los proyectos coloniales (aun cuando se diga que la Modernidad es justo la negación de dichos proyectos) o del rechazo, incluso, de la posibilidad de una civilización que no sea occidental. Estos acontecimientos sirven de base para una Modernidad que produce racionalidades capaces de justificar la expoliación y la violencia, como el costo necesario para realizarse a sí misma. Es decir, la Modernidad trae consigo el progreso y, por lo tanto, tiene el imperativo de realizarse a lo largo y ancho del mundo, aplastando a su paso muchas florecillas inocentes, como describe Hegel (2004). Por ello, para Rosenzweig (2006 y 2015) la Modernidad occidental es una ontología de la guerra. ${ }^{5}$

Si se permite señalar contradicciones, una de las más agudas es aquella que sirve de pilar a la Modernidad: el universalismo. En justicia, basta mencionar que un verdadero universalismo tendría que reclamar la cancelación de un proyecto unívoco basado en la idea de progreso y en la inevitabilidad del capitalismo. Sobre el progreso, Benjamin insiste que este es indisociable de la catástrofe.

Así, el infierno no es lo que espera a los hombres, el infierno es esta época (Benjamin, 2013). Aunado, el capitalismo no es su corrección sino su fuerza 5 Para una ampliación a este problema, se sugieren los trabajos de Taub (2013 y 2017), Navarrete (2017) y Piñeiro- Iñíguez (2017). 
realizativa; es decir, un verdadero universalismo tendría que reclamar la cancelación del proyecto moderno y revertirlo en dirección a los proyectos hundidos.

En este contexto se comprende la audacia de Benjamin por invertir la orientación temporal de la modernidad, por revertir el culto al futuro e iniciar un ajuste de cuentas con el pasado, una incómoda tarea intelectual por pensar la posibilidad de reestructurar el tiempo histórico a partir de una combinación dialéctica y teológica expuesta en su idea de un compromiso mesiánico (Mancera, 2005: 146).

Lo que aquí se desbroza es que el olvido de la felicidad como fin político, olvido que ha traído como consecuencia la naturalización del sufrimiento, convierte en anacrónico todo propósito lanzado al futuro. Benjamin (2010d) no va hacia Aristóteles para definir la felicidad. Consciente de los límites de su época, sostiene que felicidad es poder vivir una vida sin miedo y sin horror. Por ello la urgencia del pensamiento se dirige directamente hacia el presente y este no está completo sin la corrección del sufrimiento causado a todos los vencidos por la Modernidad.

Siguiendo a Werner Hamacher, Taub (2015) afirma que la Modernidad significa derrumbamiento $y$, por lo tanto, supone una puerta siempre abierta a otras posibilidades, en este caso, mesiánicas, en el sentido que Benjamin les adjudica: todo hombre dispone de una leve fuerza mesiánica con la cual puede hacer posible la llegada del Mesías. No se está diciendo otra cosa diferente a que el presente es inconcebible sin el pasado. Mesiánico no es el problema de las doctrinas religiosas. Al contrario, se puede sostener que es el umbral conflictivo en el cual la religión y la historia se encuentran. Es al hombre apurado por el presente al que le corresponde modificar el tiempo lineal y homogéneo del progreso. Si este resulta tan incuestionable e imparable, no es por algo distinto a lo que concurre con la fantasía de alcanzar una humanidad sin fractura, que se desplaza hacia un tiempo ontológicamente inexistente: el futuro.

\section{Referencias}

Agamben, Giorgio (1998), Homo sacer. El poder soberano y la nuda vida, España: Pre-Textos. Agamben, Giorgio (2005), "Una biopolítica menor. Entrevista con Giorgio Agamben”, en Ugarte-Pérez, Javier [comp.], La administración de la vida. Estudios biopoliticos, España: Anthropos.

Agamben, Giorgio (2007), Lo abierto. El hombre y el animal, Argentina: Adriana Hidalgo. Agamben, Giorgio (2010), Medios sin fin. Notas sobre la politica, España: Pre-Textos.

Agamben, Giorgio (2014), Estado de excepción. Homo sacer, vol. II, núm. 1, Argentina: Adriana Hidalgo. 
Annas, Julia (2004), Una brevisima introducción a la filosofía Antigua, México: Océano.

Aristóteles (2007), Politica, Argentina: Losada.

Atiles-Osoria, José (2015), "Del estado de necesidad al estado de excepción: Reflexiones sobre Carl Schmitt”, en Cátedra, núm. 13, Panamá: Universidad de Panamá.

Benjamin, Walter (1985), "Kapitalismus als religion”, en Gesammelte Schriften IV, vol. 1, Alemania: Suhrkamp.

Benjamin, Walter (2010a), "Destino y carácter”, en Obras. Libro II, vol. 1, España: Abada.

Benjamin, Walter (2010b), "Karl Krauss”, en Obras. Libro II, vol. 1, España: Abada.

Benjamin, Walter (2010c), "Hacia la crítica de la violencia”, en Obras. Libro II, vol. 1, España: Abada.

Benjamin, Walter (2010d), “Calle de dirección única”, en Obras. Libro IV, vol. 1, España: Abada.

Benjamin, Walter (2012a), "La obra de arte en la época de su reproductibilidad técnica”, en Obras. Libro I, vol. 2, España: Abada.

Benjamin, Walter (2012b), "Sobre el concepto de historia", en Obras. Libro I, vol. 2, España: Abada.

Benjamin, Walter (2013), Obra de los pasajes. Obras. Libro V, vol. 1, España: Abada.

Benjamin, Walter (2015), Obra de los pasajes. Obras. Libro V, vol. 2, España: Abada.

Cuesta, Micaela (2013), "Variaciones sobre la felicidad. Hannah Arendt, G. W. F. Hegel, Walter Benjamin”, en Anacronismo e Irrupción, núm. 4, Argentina: Universidad de Buenos Aires.

Foucault, Michel (1996), La vida de los hombres infames, Argentina: Altamira.

Foucault, Michel (2002), Historia de la sexualidad. 1. La voluntad de saber, México: Siglo XXI.

Foucault, Michel (2005), Vigilar y castigar. Nacimiento de la prisión, Argentina: Siglo XXI.

Galcerà, David (2016), La pregunta por el hombre: Primo Levi y la zona gris, España: Anthropos y México: Universidad Autónoma Metropolitana Iztapalapa.

Hegel, Georg (2004), Lecciones sobre la filosofía de la historia universal, España: Alianza.

Hernández, Diego (2008), "Liberalismo totalitario. Derecho, biopolítica y estado de excepción en Agamben”, en Múnera-Ruíz, Leopoldo [ed.], Normalidad y excepcionalidad en la politica (Schmitt, Agamben, Žižek y Virno), Colombia: Universidad Nacional de Colombia.

Hincapié-García, Alexánder (2014), “La 'cuestión' del mal y la Modernidad. A propósito de una lectura desde Walter Benjamin”, en Revista de Estudios Sociales, núm. 50, Colombia: Universidad de los Andes.

Hincapié-García, Alexánder (2016), “Imaginación política', historia e impulso antinarrativo. El retorno revolucionario de Walter Benjamin (1892-1940)”, en EscobarGarcía, Bibiana et al. [comp.], Modernidad y politica. Sobre la pregunta antropológica, Colombia: Ediciones Unaula.

Levi, Primo (2010), "Prefacio a 'Auschwitz’ de León Poliakov", en Vivir para contar. Escribir tras Auschwitz, España: Alpha Decay.

Levi, Primo (2012), "Si esto es un hombre”, en Trilogia de Auschwitz, España: Océano.

Löwy, Michael (2012), Walter Benjamin: aviso de incendio. Una lectura de las tesis "Sobre el concepto de historia”, Argentina: Fondo de Cultura Económica.

Mancera, Francisco (2005), “Tiempo mesiánico”, en Echeverría, Bolívar [comp.], La mirada del ángel. En torno a las Tesis sobre la historia de Walter Benjamin, México: Universidad Nacional Autónoma de México. 
Marcuse, Herbert (2011), El carácter afirmativo de la cultura, Argentina: El cuenco de plata. Mate, Reyes (2003a), Por los caminos del exterminio, España: Anthropos.

Mate, Reyes (2003b), Memoria de Auschwitz. Actualidad moral y politica, España: Trotta. Marx, Karl (2012), “Crítica al programa de Gotha”, en Textos selectos, España: Gredos.

Marx, Karl (2007), Manuscritos de economía y filosofía, España: Alianza.

Navarrete, Roberto (2017), Los tiempos del poder. Franz Rosenzweigy Carl Schmitt, España: Escolar y Mayo editores.

Nosseto, Luciano (2013), "La felicidad de los antiguos y de los modernos. Leo Strauss, Alexandre Kojève y la cuestión de los géneros de vida”, en Anacronismo e Irrupción, núm. 4, Argentina: Universidad de Buenos Aires.

Orejuela-Botero, Nicolás (2011), Los estados de excepción. Una aproximación desde los mecanismos de control, Colombia: Universidad de San Buenaventura.

Piñeres-Sus, Juan David (2016), "Antropología e idealidad. Algunas reflexiones sobre crueldad y superfluidad”, en Escobar-García, Bibiana et al. [comp.], Modernidad y politica. Sobre la pregunta antropológica, Colombia: Ediciones Unaula.

Piñeres-Sus, Juan David (2017), Lo humano como ideal regulativo. Imaginación antropológica: cultura, formación y antropología negativa, Colombia: Universidad de Antioquia.

Piñeiro-Iñíguez, Carlos (2017), Franz Rosenzweig y la teología politica judia contemporánea, Argentina: Ariel.

Rosenzweig, Franz (2006), La estrella de la redención, España: Sígueme.

Rosenzweig, Franz (2015), Escritos sobre la guerra, España: Sígueme.

Ruíz-Gutiérrez, Adriana (2013), La violencia del derecho y la nuda vida, Colombia: Universidad de Antioquia.

Runge, Andrés y Muñoz, Diego (2010), “Crisis y aporías de la educación en la sociedad moderna occidental: elementos iniciales para un debate antropológico-pedagógico sobre educación y posmodernidad", en Revista Colombiana de Educación, núm. 59, Colombia: Universidad Pedagógica Nacional.

Schmitt, Carl (2011), Teoría de la constitución, España: Alianza.

Sucasas, Alberto (2000), "Anatomía del lager (Una aproximación al cuerpo concentracionario)", en Isegoría, núm. 23, España: Consejo Superior de Investigaciones Científicas.

Taub, Emmanuel (2013), Mesianismo y redención. Prolegómenos para una teología politica judia, Argentina: Miño y Dávila.

Taub, Emmanuel (2015), "Rememoración judía y tiempo mesiánico: sobre la potencia y la esperanza en el lenguaje”, en Messina, Aïcha et al. [comp.], Filosofía y mesianismo. Lenguaje, temporalidad y politica, Chile: Metales Pesados.

Taub, Emmanuel (2017), "Historia universal y apocalipsis: un comentario sobre el estado del mundo en Franz Rosenzweig y Carl Schmitt”, en Revista Ratio Juris, núm. 12, Colombia: Universidad Autónoma Latinoamericana.

Tobón, Mary (2011), "Suspensión de garantías: la muerte tibia de la constitución política de Colombia de 1991", en Pensamiento jurídico, núm. 32, Colombia: Universidad Nacional de Colombia.

Trujano, María (2013), “Del hedonismo a las felicidades efímeras”, en Sociológica, núm. 79, México: Universidad Autónoma Metropolitana.

Vigo, Alejandro (2007), Aristóteles. Una introducción, Chile: Instituto de Estudios de la Sociedad.

Weber, Max (2003), La ética protestante y el espíritu del capitalismo, México: Fondo de Cultura Económica. 
Alexánder Hincapié-García. Doctor en Educación de la Universidad de Antioquia. Realiza su estancia doctoral en la Universidad Nacional Autónoma de México (UNAM). Su tesis doctoral obtuvo la máxima calificación, Summa Cum Laude. Reconocido como Investigador Asociado por Colciencias. Líneas de investigación: filosofía judía, teología política y pedagogía general. Publicaciones recientes: Hincapié-García, Alexánder (2016), "Formación y praxis pedagógica revolucionaria: los escritos de juventud de Marx y Benjamin”, en Andamios. Revista de Investigación Social, núm. 32, México: Universidad Autónoma de la Ciudad de México; Hincapié-García, Alexánder (2015), "Revisiones críticas al concepto de género. Apuntes para la teoría social contemporánea”, en Universitas Humanística, núm. 79, Colombia: Universidad Javeriana; Hincapié-García, Alexánder (2014), “La 'cuestión' del mal y la Modernidad. Una lectura a propósito de Walter Benjamin”, en Revista de Estudios Sociales, núm. 50, Colombia: Universidad de los Andes.

Bibiana Escobar-García. Doctora en Filosofía de la Universidad Pontificia Bolivariana. Su tesis doctoral se titula La esfera pública y la natalidad en Hannah Arendt. Reconocida como Investigadora Asociada por Colciencias. Líneas de investigación: género y derecho, diversidad cultural y política. Publicaciones recientes: Escobar-García, Bibiana y Uribe, Isabel Cristina [coordinadoras] (2016), Apropiación social del conocimiento: fundamentos para la innovación y la investigación, Colombia: Universidad Autónoma Latinoamericana; y Escobar-García, Bibiana [compiladora] (2011), Género y Derecho, Colombia: Universidad Autónoma Latinoamericana. 